\title{
Serrated polyposis syndrome and colonoscopic surveillance: who is it safe to follow?
}

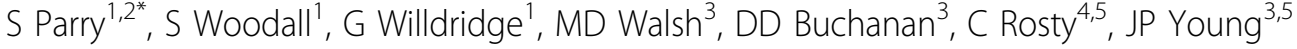 \\ From Familial Aspects of Cancer 2011 Research and Practice: A combined meeting of kConFab, Australian \\ Breast Cancer Family Study, Australian Colorectal Cancer Family Study, Australian Ovarian Cancer Study, \\ Family Cancer Clinics of Australia and New Zealand and kConFab \\ Kingscliff, Australia. 23-26 August 2011
}

\begin{abstract}
Aim
To assess colorectal cancer (CRC) risk during colonoscopy surveillance in a cohort of patients with the serrated polyposis syndrome (SPS).
\end{abstract}

\section{Method}

Colonoscopy and histology records from January 2000 to time of interview for 67 New Zealand patients, meeting WHO criteria for a diagnosis of SPS and enrolled in the Genetics of Serrated Neoplasia study, were reviewed. Polyp demographics, smoking status and family history of cancer were recorded.

\section{Results}

Of 67 patients 18 presented with CRC (mean age 57yrs, 12 Female). Only one of 18 reported a first degree relative (FDR) with CRC. Over a median follow-up of 8 years from time of surgery with an average interval of 16 months between colonoscopies, two patients developed metachronous CRC: one identified at prophylactic completion colectomy and one in association with first diagnosis of SPS 19 yrs following initial CRC and 30 months after a previous colonoscopy. Of 45 patients with polyps alone (mean age 48 yrs, 27 female) followed for a median of 9 years with an average interval of 15 months between colonoscopies, none developed CRC despite 33 having multiple pan colonic polyps. Of these $33,70 \%$ had an adenoma, $18 \%$ a sessile serrated polyp and $53 \%$ polyps $>10 \mathrm{~mm}$. A FDR with CRC was reported in 14/45 (31\%). Four patients with multiple pan colonic polyps and no FDR with CRC underwent prophylactic subtotal colectomy (mean age 58 yrs, 3 females) after being followed for a median of 5 years with an average interval between colonoscopies of 8 months. All had adenomas and one a sessile serrated polyp. No significant smoking effect was seen in any group.

\section{Conclusion}

If endoscopic control is feasible, SPS patients can be judiciously managed by frequent surveillance colonoscopy.

Author details

${ }^{1}$ New Zealand Familial Gastrointestinal Cancer Registry, Auckland Hospital, New Zealand. 'Department of Gastroenterology, Middlemore Hospital, Auckland, New Zealand. ${ }^{3}$ Familial Cancer Laboratory, QIMR, Herston, Queensland, Australia. ${ }^{4}$ Department of Molecular and Cellular Pathology, University of Queensland, Queensland, Australia. ${ }^{5}$ School of Medicine, University of Queensland, Herston, Queensland, Australia.

Published: 12 April 2012

doi:10.1186/1897-4287-10-S2-A20

Cite this article as: Parry et al:: Serrated polyposis syndrome and colonoscopic surveillance: who is it safe to follow? Hereditary Cancer in Clinical Practice 2012 10(Suppl 2):A20.

${ }^{1}$ New Zealand Familial Gastrointestinal Cancer Registry, Auckland Hospital,

New Zealand

Full list of author information is available at the end of the article

(c) 2012 Parry et al; licensee BioMed Central Ltd. This is an Open Access article distributed under the terms of the Creative Commons 